\title{
MEMÓRIAS E NARRATIVAS DO CÁRCERE: TECENDO DIÁLOGOS ENTRE A EDUCAÇÃO DE JOVENS E ADULTOS, A ARTE E A UNIVERSIDADE
}

\author{
Elisangela André da Silva Costa ${ }^{1}$ \\ Ana Lúcia Nobre da Silveira ${ }^{2}$ \\ Elcimar Simão Martins ${ }^{3}$
}

\begin{abstract}
Resumo: O presente texto teve como objetivo refletir sobre o potencial pedagógico e emancipatório da EJA para as Pessoas Privadas de Liberdade no Maciço de Baturité - Ceará. A reflexão sobre os desafios históricos de reconhecimento da EJA como um direito no contexto brasileiro foi tomada como ponto de partida para as reflexões, passando pelos contributos das experiências estéticas desenvolvidas no contexto educativo das prisões, culminando com os desafios presentes no ingresso e permanência de pessoas privadas de liberdade na educação superior. Ao longo do estudo, são apresentadas discussões sobre a perspectiva problematizadora da educação, compreendida como um horizonte formativo necessário à leitura crítica e à transformação da realidade, no interior da qual são criadas oportunidades de desenvolvimento da sensibilidade, através da arte, estimulando a criatividade, $o$ diálogo, a humanização e a busca de novos espaços formativos, como o contexto universitário. Para a compreensão mais ampla e profunda da formação vivida a partir do contexto do cárcere, dialogamos com um jovem privado de liberdade, recém ingresso na educação superior, através da construção de narrativas autobiográficas. Os resultados afirmam o potencial transformador, emancipatório e humanizador da EJA nos espaços de privação de liberdade, que se materializa através da articulação entre as políticas educacionais de inclusão vigentes no Brasil, no início do Sec. XXI, e as posturas dos educadores que atuam junto a estes sujeitos, expressando sensibilidade, compromisso político e ético com a educação, com os educandos e com a sociedade.
\end{abstract}

Palavras-chave: EJA. Educação Prisional. Educação Superior. Arte. Memória.

\footnotetext{
${ }^{1}$ Doutora em Educação pela Universidade Federal do Ceará. Professora Adjunta da Universidade da Integração Internacional da Lusofonia Afro-Brasileira - UNILAB. Contato: elisangelaandre@unilab.edu.br. 2 Mestre em Sociobiodiversidade pela Universidade da Integração Internacional da Lusofonia AfroBrasileira - UNILAB. Contato: alns_prof@yahoo.com.br.

${ }^{3}$ Doutor em Educação pela Universidade Federal do Ceará. Professor Adjunto da Universidade da Integração Internacional da Lusofonia Afro-Brasileira - UNILAB. Contato: elcimar@unilab.edu.br.
} 


\title{
MEMORIES AND NARRATIVES OF THE CARCERE: DRAWING DIALOGUES BETWEEN YOUTH AND ADULT EDUCATION, ART AND UNIVERSITY
}

\begin{abstract}
The present text had as objective to reflect on the pedagogical and emancipatory potential of the EJA for the Persons Deprived of Liberty in the Maciço de Baturité - Ceará. The reflection on the historical challenges of recognition of the EJA as a right in the Brazilian context was taken as a starting point for the reflections, through the contributions of the aesthetic experiences developed in the educational context of the prisons, culminating with the challenges present in the entry and permanence of people deprived of liberty in higher education. Throughout the study, we present discussions about the problematizing perspective of education, understood as a formative horizon necessary for critical reading and the transformation of reality, within which opportunities for the development of sensitivity are created through art, stimulating creativity, dialogue, humanization and the search for new formative spaces, such as the university context. For the broader and deeper understanding of the formation lived from the context of the prison, we dialogued with a young man deprived of freedom, recently admitted to higher education, through the construction of autobiographical narratives. The results affirm the transforming, emancipatory and humanizing potential of the EJA in spaces of deprivation of liberty, materialized through the articulation between the educational policies of inclusion in force in Brazil at the beginning of Sec. XXI and the positions of the educators who work together to these subjects, expressing sensitivity, political and ethical commitment to education, students and society.
\end{abstract}

Keyuwords: EJA. Prison Education. College education. Art. Memory.

\section{Introdução}

O presente texto tem como objetivo compreender o potencial pedagógico e emancipatório da Educação de Jovens e Adultos (EJA) no contexto de Pessoas Privadas de Liberdade (PPL) no Maciço de Baturité Ceará.

Tomamos como ponto de partida a reflexão sobre os desafios históricos de reconhecimento da EJA como um direito no Brasil, reafirmando a perspectiva problematizadora da educação como um horizonte formativo necessário à leitura crítica e à transformação da realidade. Agrega-se a este 
movimento de desvelamento, trazendo luzes ao contexto desafiador da educação no cárcere, a experiência estética proporcionada pela arte, que confere à EJA uma perspectiva sensível e reflexiva para a formação, estimulando a criatividade, o diálogo, a humanização e a busca de novos espaços formativos.

Para acessarmos o universo das experiências dos sujeitos que partilham desse espaço formativo, utilizamos narrativas (auto) biográficas (SOUZA, 2007; JOSSO, 2007) para mergulhar nas memórias de Pássaro Livre4, um homem que em 2018 encontrava-se privado de liberdade, cumprindo pena ${ }^{5}$ na Cadeia Pública de Pacoti - Ceará. A partir de suas memórias, articulamos diálogos com três fortes fios: a EJA, a Arte e a Universidade.

Os resultados da investigação apontam para o potencial transformador, emancipatório e humanizador da EJA nos espaços de privação de liberdade, tendo em vista o contributo das políticas educacionais de inclusão vigentes no início do Sec. XXI, articuladas ao exercício de sensibilidade e compromisso político e ético empreendido pelos educadores que atuam junto aos sujeitos nos diferentes espaços formativos.

\section{A Educação de Jovens e Adultos e as Pessoas Privadas de Liberdade}

A atual Lei de Diretrizes e Bases da Educação Nacional - LDB 9394/96 (BRASIL, 1996) apresenta a EJA como uma modalidade de ensino que tem como objetivo oferecer à população jovem e adulta a oportunidade de retomada de processos de escolarização interrompidos antes de sua conclusão ou que sequer foram iniciados. Contemplando o público jovem a partir de 15 anos no Ensino Fundamental e a partir dos 18 anos para o Ensino Médio, a EJA pode ser organizada de modo presencial e/ou semipresencial, ou ainda através do reconhecimento dos conhecimentos e habilidades adquiridos pelos educandos por meios informais, mediante a submissão dos mesmos a exames materializados através de processos de avaliação externa.

Dadas as características do público que atende e sua relação com a escolarização, o Ministério da Educação (MEC) estabeleceu diretrizes (BRASIL,

${ }^{4}$ Nome fictício para preservar identidade do participante.

${ }^{5} \mathrm{O}$ motivo pelo qual Pássaro Livre encontrava-se privado de liberdade não foi objeto de nosso estudo. 
2000) que orientam a organização curricular da EJA no Brasil, estabelecidas as seguintes funções:

Reparadora, relacionada à entrada no circuito dos direitos civis e ao reconhecimento da igualdade ontológica entre os seres humanos, cabendo à EJA colaborar para a restauração do direito a uma escola de qualidade, que foi negado aos jovens e adultos pouco ou não escolarizados;

Equalizadora, a ser materializada através da promoção de maiores oportunidades aos educandos da EJA, harmonizando a intensidade de diferentes ações no processo de (re)entrada de jovens, adultos e idosos no sistema educacional, visando novas inserções no mundo do trabalho, na vida social, nos espaços da estética e na abertura dos canais de participação;

Qualificadora, que simboliza o próprio sentido da EJA, fundamentado no caráter de incompletude do ser humano e em todo o potencial de Ser Mais existente em cada sujeito.

O sistema educacional brasileiro, a partir do conjunto de referências legais que o estruturam, assegura aos jovens e adultos em termos formais e gratuitamente, oportunidades educacionais apropriadas, considerando suas peculiaridades, interesses e condições de vida e de trabalho, dando oportunidade aos interessados de darem continuidade aos estudos. É imperioso destacar que o direito à educação não se resume à garantia da matrícula, estendendo-se às estratégias para permanência e efetiva aprendizagem (SILVEIRA; MARTINS; MACHADO, 2016).

Ao longo de sua existência, a EJA enfrentou e superou vários obstáculos econômicos, sociais e/ou políticos, colaborando, através da educação, para a transformação de uma parcela considerável da sociedade, historicamente privada de oportunidades educacionais. Convém destacar que o reconhecimento da EJA como uma modalidade de ensino no contexto brasileiro é fruto da articulação e da luta histórica de movimentos sociais e, também, dos educadores e das escolas de educação básica que vêm desenvolvendo um trabalho comprometido política e pedagogicamente com a inclusão e a emancipação dos sujeitos através da educação.

A partir do exposto, o direito à matrícula, a transporte, merenda escolar, materiais didáticos é reflexo de conquistas importantes, como a inclusão da EJA no Fundo de Manutenção e Desenvolvimento da Educação Básica-FUNDEB, a partir do ano de 2007. Tal inclusão simboliza possibilidades de ruptura do caráter descontínuo e pontual que se constituiu como 
característica histórica do financiamento das ações voltadas a EJA (COSTA, 2014). Tais avanços, no entanto, permanecem cercados por desafios que colocam em permanente tensão o escrito e o vivido nas políticas educacionais, tendo em vista os projetos de sociedade em permanente embate no contexto brasileiro e que interferem de forma direta na vivência plena dos direitos pelos cidadãos.

Destacamos que direito à educação vem sendo confirmado como caminho de inclusão para muitos jovens e adultos, que tem permitido aos mesmos possibilidades de avanço e continuidade aos estudos, o ingresso em uma universidade, a profissionalização e a expansão das oportunidades. Nesse contexto, o papel do educador é fundamental. A crença no potencial do educando e a mobilização dos conhecimentos de mundo para a construção de novos conhecimentos fazem com que o processo educativo conduzido pelos educadores mobilize esses sujeitos, fazendo-os acreditar em sua capacidade de desenvolvimento intelectual e profissional.

A partir do horizonte formativo apresentado, a EJA caminha para superar a perspectiva compensatória, pautada na educação bancária que valoriza o acúmulo de informações, em direção a uma educação problematizadora e dialógica que valorize as experiências de vida dos sujeitos, oportunizando a emancipação e a humanização dos mesmos. Em sua essência, a EJA possui público, organização, metodologia e um currículo voltado ao atendimento das necessidades dos educandos, ajudando-os na compreensão e na superação dos novos e constantes desafios postos pela vida.

A diversidade de experiências e identidades dos educandos nos convidam, como educadores, a pensar sobre as mais distintas realidades, como as questões relacionadas a campo e cidade; relações intergeracionais, de gênero e etnicorraciais; além das que dizem respeito a situações de itinerância ou privação de liberdade. Muitos são os caminhos já traçados pelo público da EJA e muitos são os obstáculos a serem superados para alcançarem a emancipação. No entanto, há que se registrar também as distintas possibilidades de reescrita das histórias de vida, dentre as quais destacamos aquela que se desenvolve nos contextos das prisões.

De acordo com Soares (2015) a EJA no sistema prisional foi sendo historicamente fortalecida a partir da promulgação da Constituição Federal de 1988 (BRASIL, 1988) e da LDB no 9394/96 (BRASIL, 1996), que mobilizaram a 
construção de outros documentos importantes, como as Diretrizes Curriculares Nacionais para a EJA (BRASIL, 2000) que fizeram pela primeira vez referência ao direito à matrícula de pessoas encarceradas na EJA. Ressaltamos, ainda, que a oferta da Educação em Prisões, de acordo com suas particularidades não pode ser considerada um benefício ao privado, mas um direito adquirido a partir do diálogo estabelecido entre as legislações educacionais já mencionadas e outras existentes, como a Lei no 7.210 (BRASIL, 1984), que institui a Lei de Execução Penal (LEP); a Lei no 12.433 (BRASIL, 2011), que alterou a Lei de Execução Penal, modificando a sistemática de remição de pena por trabalho ou estudo; e a Declaração dos Direitos Humanos (ONU, 1948).

Esse conjunto de dispositivos legais oferece à população carcerária a oportunidade de vivenciar práticas educativas que possibilitem a interligação entre os sujeitos e o mundo através do ato de conhecer (FREIRE, 1983), mesmo em contextos de privação da liberdade.

É interessante observarmos que os educandos, a priori, não se dão conta da verdadeira dimensão que o processo educativo pode significar em suas vidas e o potencial transformador nele guardado. Tal questão pode ser observada no relato de Pássaro Livre ${ }^{6}$ sobre o retorno aos estudos no sistema prisional:

Primeiramente, o que me levou a voltar a estudar foi para eu ver se concluía o Ensino Médio e o outro dos motivos era porque não tinha nada para fazer, aí eu achei bom estudar porque eu já ficava um pouco livre da cela, e o outro foi pela remissão (PÁSSARO LIVRE).

Em uma escala gradativa, Pássaro Livre elencou que a função da escola na vida das pessoas privadas de liberdade é: i) ajudar a remir a pena; ii) dar continuidade aos estudos e iii) entrar na universidade. Seu depoimento revela dimensões pragmáticas relacionadas ao desejo de continuidade e conclusão dos estudos, assim como de enfrentar o dia a dia, que “[...] é

\footnotetext{
${ }^{6}$ Seguiremos a partir deste ponto do texto dialogando com Pássaro Livre, sujeito desta investigação. Assim, iremos inicialmente apresentá-lo. Ele é natural de Aracoiaba, município pertencente à região do Maciço de Baturité no estado do Ceará e teve sua formação marcada por processos de descontinuidade decorrentes de questões familiares relacionadas ao abandono materno e rearranjos familiares possíveis, construídos entre o pai e a avó.
} 
marcado pelo ócio, aqui entendido não como um momento de descanso, podendo ser um produtor de reflexões e criatividade, mas como um prolongado tempo de ausência de atividade" (CAMPOS, 2015, p. 50).

No que concerne à remição da pena em razão do trabalho ou do estudo, a Lei no 12.433 (BRASIL, 2011) alterou a Lei de Execução Penal, apresentando mudança no modo de contar a diminuição dos dias remidos da pena. O artigo 126 da referida lei concede a remição de pena pelo estudo, não importando se o detento é provisório ou definitivo, estabelecendo que o PPL remirá "I - 1 (um) dia de pena a cada 12 (doze) horas de frequência escolaratividade de ensino fundamental, médio, inclusive profissionalizante, ou superior, ou ainda de requalificação profissional - divididas, no mínimo em três dias". Com relação ao trabalho, o privado de liberdade remirá "II- 1 (um) dia de pena para cada três dias de trabalho".

Interessante observar que a partir das vivências como estudante na unidade prisional, Pássaro Livre foi percebendo as possibilidades de ampliação de seu universo de experiências. Segundo ele,

Logo no começo que eu voltei a estudar, eu não sabia que poderia entrar numa universidade, quando eu voltei a estudar foi porque eu pensava mais na remição e em ocupar o tempo. Quando foi no final do ano, que a professora disse que eu podia fazer o ENEM, receber o diploma do Ensino Médio e se passasse ainda podia ir para a universidade, aí eu fiquei mais animado (PÁSSARO LIVRE).

O educando seguiu falando dos contributos trazidos pelos conhecimentos adquiridos para a sua vida, relatando:

Pra mim melhorou, tive o retorno de tudo que eu já tinha estudado, começou tudo a voltar na minha cabeça todo o aprendizado e eu fui aprendendo mais com a professora. Hoje leio mais, pesquiso mais, me informo mais, porque exige muito, minha nova atividade ${ }^{7}$ exige mais, que eu esteja informado, esteja atualizado.

${ }^{7}$ Sobre esse aspecto da vida atual de Pássaro Livre, que diz respeito à vida universitária, detalharemos mais adiante. 
A educação no contexto prisional trouxe outros horizontes a Pássaro Livre, ultrapassando a ideia de ocupação do tempo ou de remissão de pena, ventilando a possibilidade de alçar outros voos, de ocupar uma vaga na Universidade.

$\mathrm{Na}$ oportunidade de se educar e/ou reeducar, a obrigação do poder público torna-se ação indispensável para atender aos parâmetros de reintegração social, "[...] o que implica remeter-se à ideia de que o interno volte à sociedade em condições de convívio social compatível com os ditames impostos pela própria sociedade" (ARAÚJO, 2013, p. 14). Nesse sentido, a educação em sistemas penitenciários alcança sua função social quando possibilita ao reeducando a visão do mundo com uma perspectiva de mudança de atitude.

Segundo Fagundes, Souza e Conceição (2012, p. 11), a educação de pessoas privadas de liberdade é algo complexo, pois envolve “[...] alunos em situações peculiares, o que justifica a necessidade de estudos, reflexões e, especialmente, projetos sociais voltados para os excluídos, os marginalizados, os insatisfeitos, a maioria perdedora". Em consonância com a importância da EJA no ambiente prisional, Silveira (2018, p. 39), afirma que é “[...] necessário não só ofertar a educação em prisão, mas também encorajar e aprimorar o processo de ensino e aprendizagem, no interior das unidades prisionais, para que o reeducando torne-se preparado para a sua restituição social".

Pássaro Livre relatou que o melhor momento da aula é o de interatividade com os outros privados de liberdade, que envolvem as atividades em grupo, a partilha de experiências e a própria rotina do contexto prisional. O intuito da escola, em especial da educação para os privados de liberdade, é contribuir para o desenvolvimento intelectual por meio da socialização, da valorização do conhecimento, tido como maior riqueza do sujeito enquanto ser social, possibilitando o empoderamento através do ato de conhecer e da leitura crítica da realidade.

Ao conversarmos sobre os principais benefícios da educação para uma pessoa privada de liberdade, o educando mexeu em seu baú de lembranças e categoricamente afirmou:

Pra mim o maior benefício é que eu pude me reciclar, aprender, rever novamente o que já tinha aprendido, porque eu havia parado há muitos anos. A professora ficou até assim, porque já fazia catorze anos [sem 

passar no ENEM e consegui entrar numa faculdade, e agora só Deus sabe pra onde a gente vai (PÁSSARO LIVRE).

Pássaro Livre soube valorizar a oportunidade que teve no ambiente prisional: estudou, realizou o Exame Nacional do Ensino Médio (ENEM) para pessoas privadas de liberdade e com a pontuação obtida conseguiu uma vaga em curso de licenciatura em uma universidade pública federal.

A postura de Pássaro Livre diante do processo formativo vivido no Cárcere reforça a compreensão de Gadotti (1997, p. 20) quando afirma que “O papel da escola consiste em colocar o conhecimento nas mãos dos excluídos de forma crítica, porque a pobreza política produz pobreza econômica". Alinha-se a essa compreensão o pensamento de Freire (1996, p. 19) quando ressalta que é preciso "assumir-se como ser social e histórico, como ser pensante, comunicante, transformador, criador, realizador de sonhos, capaz de ter raiva porque capaz de amar", revelando o desafio de ser e estar no mundo, buscando, portanto, intervir de forma produtiva para mudar a realidade.

Desde que as condições sejam asseguradas, o educando, em especial, o privado de liberdade, precisa também assumir-se como corresponsável de seu processo de aprendizagem, compreendendo que o conhecimento é a chave para a sua libertação, ou seja, a ressocialização.

\section{A Arte no cárcere como possibilidade de humanização}

A formação humana pode ser compreendida de modo geral como um processo quer proporciona aos sujeitos a construção de si mesmos, por meio das experiências que a vida oportuniza e da reflexão acerca dos ensinamentos que as mesmas favorecem. Desta feita, formar-se é uma atividade em que cada um de nós faz-se e refaz-se.

Os processos formativos vividos no cárcere oportunizam aos sujeitos, cotidianamente, perceber a si mesmos nas relações que estabelecem com os outros e com a totalidade, identificando os limites e possibilidades presentes nesse processo e o modo como interferem na (re) construção de seu processo identitário.

Segundo Larrosa (2014, p. 25), o processo de formar-se implica em “[...] parar para pensar, parar para olhar, parar para escutar, pensar mais 
devagar, olhar mais devagar, e escutar mais devagar; parar para sentir, sentir mais devagar, demorar-se nos detalhes, suspender a opinião, suspender o juízo, suspender a vontade". Nesse exercício de escutar o outro, de demorar-se na realização de coisas simples, de permitir-se espaço e tempo é que o homem se forma. Tais atitudes, convém ressaltar, não se dão de forma espontânea, sendo aprendidas a partir de processos educativos e da reflexão, rompendo com referenciais vinculados à racionalidade técnica, sustentada no consumo acrítico de informações, assim como no distanciando entre o conhecer, o sentir e o agir.

Para pensar a educação, portanto a formação humana, é necessário partir das experiências e dos sentidos que os sujeitos conferem às mesmas. É necessário problematizar a realidade e suas diferentes faces, de modo que as experiências vividas pelos indivíduos possam reafirmar-se como uma importante referência para contribuir com uma formação que possibilite o desenvolvimento da sensibilidade e do senso crítico, fundamentais à humanização.

A educação, na perspectiva apresentada, se constitui como uma experiência estética compreendida por Alvares (2015, p. 4), como base do conhecimento humano e parte essencial dos processo de ensinar e aprender que nos ensinam a estabelecer relações e a produzir sentidos. Tal movimento não pertence exclusivamente à arte, estando presente em todas as esferas e áreas do conhecimento humano, o que nos permite dizer que o processo educativo é, também, um fazer artístico e estético.

O processo formativo vivenciado por Pássaro Livre na unidade prisional permitia a vivência de atividades artísticas, através da produção de objetos decorativos a partir de dobraduras, a produção de redes a partir de sacos plásticos de arroz, desenhos, poesias, entre outras formas de expressão. Sobreo modo como ocorreu o início de suas produções artísticas na unidade prisional, o educando relata:

Eu aprendi com Fulano, com Sicrano ${ }^{8}$ e outros meninos na própria unidade [prisional]. Eu fazia só pra me distrair e pra limpar o pensamento. Porque dentro da cadeia, se a pessoa não tiver uma ocupação aí as vezes é dominado por outro pensamento. Aí eu fazia os artesanatos e por

\footnotetext{
${ }^{8}$ Omitimos os nomes dos outros privados de liberdade que foram citados.
} 
A produção de artesanato no Cárcere fazia com que as pessoas convivessem, interagissem, aprendessem entre si, ocupassem a mente, ganhassem dinheiro, se distraíssem, vendo na arte a possibilidade de expressão da vida, impregnada pela experiência e pelo belo, como propõe Nietzsche (2001) ao considerar a inteireza das coisas e não os seus recortes. É necessário perceber onde termina a arte e começa a vida. A aprendizagem maior estaria, portanto, no despertar do desejo de sermos "[...] autores de nossas vidas, principalmente pelas coisas mínimas e cotidianas" (NIETZSCHE, 2001, p. 202).

A produção de artesanato trazia dignidade aos privados de liberdade. Pode ser considerado por muitos como algo simples, mas de muito valor para os detentos. A experiência de trabalhar com a arte proporcionava um espaço-tempo de aprendizagens e vivência coletiva. Nesse sentido, "A produção artesanal era o convívio, a união dos presos, tinha mais interação, evitava mais desacordos. Todo mundo fazendo aquilo juntos, como uma equipe, eles esqueciam as desavenças, às vezes alguns pensamentos errados que tem na cadeia" (PÁSSARO LIVRE).

A lição que os artistas/privados de liberdade têm a dar aos professores traduz a compreensão de que a educação deve superar a perspectiva dicotômica com a qual tem sido tratado o conhecimento de mundo e o conhecimento científico, o sujeito que conhece e o conhecimento produzido. É necessário promover por meio das mais variadas linguagens o encantamento que liberta a palavra dos conceitos produzidos pelos intelectuais e reproduzidos acriticamente pelas escolas, tornando-as prenhes de sentidos e significados por parte dos sujeitos, como sabiamente apontava Freire (1988) ao dizer que a leitura do mundo deve preceder a leitura da palavra e que ambas não podem caminhar separadamente.

Durante séculos fomos condicionados a perceber o mundo através de prismas cartesianos que vêm privilegiando o reducionismo, a linearidade, o dualismo e o isolamento de fatos para uma melhor apreensão da realidade. $\mathrm{O}$ olhar extremamente objetivo deste paradigma influenciou as diversas instituições sociais existentes no mundo, inclusive a escola. 
A educação formal, trabalhada numa enorme parcela das instituições de ensino, traz, ainda hoje, marcas profundas do pensamento cartesiano, pois apresenta uma preocupação exacerbada com o aspecto cognitivo dos educandos, deixando em segundo plano a afetividade, a socialização, a corporeidade e a criatividade. Podemos considerar que o processo educativo, desenvolvido a partir desse pensamento, tem sido deficiente por desconsiderar a identidade dos educandos e por isso tem formado seres humanos com dificuldades de estabelecer vínculos consigo mesmos, com o outro e com a totalidade. Segundo Vecchia (2007, p. 19), "Nossa postura objetiva e mecanicista diante da realidade nos privaram da sensibilidade e, consequentemente perdemos o contato com o sagrado de cada manifestação da vida".

A partir da crítica à incapacidade histórica dos processos formativos desenvolvidos pela escola em relação à sensibilidade, podemos apontar a experiência estética como possibilidade de humanização. Assim, no que diz respeito à EJA, em especial aos privados de liberdade, é preciso superar as influências históricas pautadas no conceito de educação como compensação ou suplência, dialogando com a perspectiva de educação ao longo da vida, que liga, de forma indissociável, vida e formação, objetividade e subjetividade, indivíduo e coletividade, vivência e experiência.

Em um contexto totalmente precário, adverso e insalubre, os privados de liberdade contaram com o apoio e a sensibilidade da professora, para desenvolverem trabalhos de artesanato no interior da unidade prisional. Para produzir os objetos: "O material era tudo doado, a gente recebia da professora. E o material pra fazer os artesanatos a gente reciclava [as embalagens] dos quilos de arroz que a gente usava pra fazer o almoço e a janta e os fardos do arroz também aproveitava" (PÁSSARO LIVRE).

Educar a sensibilidade exige acesso a longos processos reflexivos, que podem ser facilitados pelo contato com a arte em suas diversas manifestações, como a música, a dança, o teatro e a as artes plásticas, compreendidas como possibilidades estéticas que carregam a potencialidade de revelar as formas como pensamos, agimos e percebemos o outro em sua inteireza. Foi esse movimento que observamos na professora da referida unidade prisional em um momento que participamos de uma certificação dos privados de liberdade. Tal movimento nos conduziu à consciência do nosso próprio existir. 
A conscientização acerca de si, do outro e da totalidade é uma importante referência para a organização do trabalho educativo, partindo do pressuposto de que o homem constrói o mundo e imprime sentido a esse mundo. Assim, mais do que assimilar ou memorizar os conhecimentos construídos historicamente pela humanidade, se faz necessária a compreensão da relação que estes constroem com a vida dos sujeitos, tanto individual, quanto coletivamente. De posse do conhecimento o homem mira o futuro, projectum: lança-se para frente, agindo e mudando sua realidade. "Este é o mundo humano: um mundo que suplanta a simples dimensão física, que existe também" enquanto possibilidade; que existe como um vir-a-ser. Em suma: o mundo também é simbólico (DUARTE JÚNIOR, 2002, p. 117).

O educando privado de liberdade fez questão de relatar como se processava a construção das redes:

\begin{abstract}
Primeiramente a gente corta o saco em tiras mais ou menos em cinco centímetros, aí amarra uma das extremidades da grade [de um portão] ou em qualquer outro objeto, aí começa a puxar para fazer a linha. Depois de feita a linha, você pega uma palheta, no caso feita de cano de PVC e vai fazendo os nós para concluir a rede, tipo rede de pesca, só que ela é aberta. E os punhos a gente aproveitava os sacos maiores para não ter muita emenda. Se tiver a linha no ponto, de um a dois dias dava para fazer o pano de rede. Tudo leva um dia, das $8 \mathrm{~h}$ às $18 \mathrm{~h}$. E todo o processo uma pessoa sozinha leva de dois a três dias (PÁSSARO LIVRE).
\end{abstract}

Ao relatar a rotina na elaboração do artesanato, em especial da rede, Pássaro Livre revela a sua dignidade de homem. Embora privado de liberdade, ele interage com outros colegas, produz arte, desenvolvendo técnicas e habilidades com o pouco que tem disponível no ambiente da unidade prisional.

De acordo com Rios (2008) ao produzirmos nossa vida realizamos uma obra análoga à obra de arte, pois nesse processo nos afirmamos enquanto sujeitos e produzimos nossa subjetividade. Transportando a questão para o campo da EJA, podemos compreender que quando se afirma a dimensão estética da formação, se fortalece a subjetividade do educando (construída processualmente através das mais variadas vivências e das práticas sociais das quais participa) e do seu jeito próprio de inventar, fazer e refazer a sua própria vida. 
Assim, concordamos com Duarte Júnior (2001, p. 205), ao abordar que no contexto atual, a educação da sensibilidade é um ato revolucionário, posto que é

[...] necessário que estejamos dispostos a alterar a nossa escala de valores, que ora coloca em primeiro plano tanto a instrumentalidade dos meios quanto os egoístas ganhos materiais que ele nos possibilita, em detrimento de uma série de qualidades vitais a nós e à natureza.

Desse modo, o reconhecimento do jovem e do adulto, em especial o privado de liberdade, como sujeito histórico e como produtor de cultura demanda da escola o olhar cuidadoso para as experiências acumuladas, para as diferentes formas de expressão utilizadas por este sujeito, para as formas como constrói suas condições materiais de existência, como se percebe no mundo e com o mundo. A partir do respeito e da valorização destas questões, os educadores passam, junto com os educandos, a tecer diálogos que possibilitem desvelar a realidade, compreender o jogo das relações sociais que oprime e desumaniza, construindo formas de intervenção na realidade que possibilitem a construção de projetos de vida por parte desses sujeitos. É nesse movimento que se percebe a indissociabilidade entre educação e vida e entre os saberes das mais diferentes ordens.

\section{A Universidade: presente do cárcere}

Como verificamos nas sessões anteriores, a vivência da educação como um direito social, subjetivo, é um desafio presente no contexto brasileiro, sobretudo para a população historicamente invisibilizada pelas políticas públicas, como o jovem e adulto analfabeto ou pouco escolarizado pertencente à classe trabalhadora, com destaque para os que se encontram privados de liberdade em decorrência de situações de conflito com a lei (SILVEIRA, 2018).

Apesar de ao longo das duas últimas décadas, o Brasil ter registrado avanços importantes referentes ao processo de democratização do acesso da população à educação, em seus diferentes níveis (IBGE, 2017), o ingresso de um educando privado de liberdade na educação superior é um fato pouco comum. O processo de inclusão de Pássaro Livre na Universidade anuncia a importância de inúmeros fatores e pessoas que se conjugam colaborando não 
só para o acesso, mas para a permanência e o sucesso deste sujeito no processo formativo por ele vivido no curso de graduação. O desafio do ingresso é relatado com emoção:

Teve uma correria na inscrição no SISU, eu vim ser contemplado e aceito na UNILAB, na universidade para estudar. E todo o processo foi um pouco corrido, porque eu ainda estava preso, não podia sair, e as vezes a gente do lado de fora fica mais fácil resolver as coisas. Aí tive que fazer procuração, a professora junto com a coordenadora do CEJA teve que correr atrás para a matrícula e a minha senhora também teve que ir na UNILAB. De vez em quando errava um documento e precisava voltar de novo. E depois eu fui aceito. Aí foi outro momento marcante, porque eu era para começar os estudos em maio de 2016, mas como eu não tinha juntado as remições nem de trabalhos e nem da escola, não pude sair! Eu só pude sair dois meses depois do começo das aulas, aí foi outro processo pra provar lá na instituição que eu não tinha faltado os dois meses, porque eles já tinham me desvinculado por falta das aulas, aí eu tive que provar que esse período que eu não fui eu estava recluso. Aí eu tive que correr atrás de novo com minha senhora, batalhar, juntar documentos, levar para a organização, eles avaliarem e abrirem o processo interno dentro da universidade para depois vir a notícia boa, que eu estava aprovado novamente, e então comecei a estudar em fevereiro de 2017 (PASSARO LIVRE).

No relato de Pássaro Livre identificamos um significativo número de pessoas que se mobilizaram para que seu direito à educação superior pudesse ser vivenciado. Freire (1987) aponta a união como um importante elemento de luta e de fortalecimento da classe trabalhadora na superação das condições de opressão, ressaltando que os desafios enfrentados são historicamente situados, demandando, portanto, uma compreensão ampla e crítica da realidade e dos determinantes que interferem de forma direta nas possibilidades de emancipação e de humanização.

Fazem parte do relato de Pássaro Livre elementos das políticas educacionais brasileiras que objetivamente representam oportunidades de inclusão da classe trabalhadora e historicamente oprimida na educação superior, quais sejam: o Sistema de Seleção Unificada (SISU), que permite ao Ministério da Educação gerenciar o ingresso de candidatos participantes do Exame Nacional do Ensino Médio em instituições públicas de educação 
superior, considerada a sistemática de cotas definidas pela Lei no 12.711 (BRASIL, 2012), alterada pela Lei no 13.409 (BRASIL, 2016), com inclusão de políticas afirmativas próprias das instituições de educação superior; e por fim, a UNILAB - Universidade criada pela Lei no 12.289 (BRASIL, 2010), no contexto Programa de Apoio a Planos de Reestruturação e Expansão das Universidades Federais (Reuni), voltado à ampliação do acesso e à permanência na educação superior brasileira.

Para Bobbio (2004, p. 09): “[...] os direitos do homem, por mais fundamentais que sejam, são direitos históricos, ou seja, nascidos em certas circunstâncias, caracterizadas por lutas em defesa de novas liberdades contra velhos poderes, e nascidos de modo gradual, não todos de uma vez e nem de uma vez por todas". Assim, o início do Sec. XXI, no Brasil, constituiu-se como um importante marco histórico de avanço dos direitos sociais e de inclusão, nos quais, finalmente se encontram visibilizadas as populações historicamente silenciadas.

A humanização e a emancipação aparecem, neste contexto, como vocação dos processos formativos a serem mobilizados pelas instituições de ensino em diálogo com a sociedade, nos diferentes espaços de socialização. Nesse sentido, a colaboração desencadeada pelos sujeitos e espaços com os quais Pássaro Livre se relaciona vem sendo fundamentais para seu crescimento pessoal, conforme se encontra expresso em seu relato:

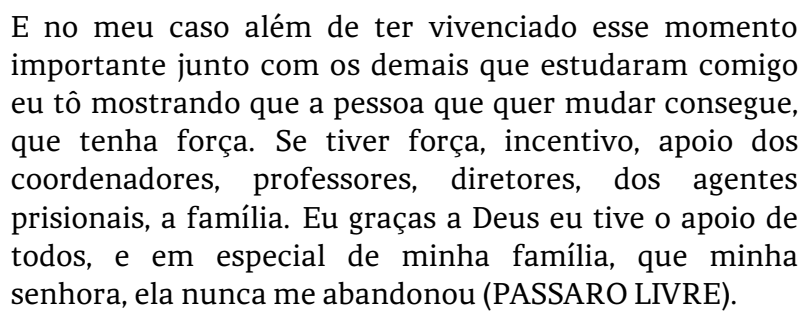

A educação e sua vocação emancipatória estão situadas no campo das construções humanas, sendo por estas desafiadas de maneira permanente, tendo em vista os diferentes projetos de sociedade em contínuo embate. Tal questão é expressa por Costa (2014, p. 39), quando afirma:

Se na sua gênese a educação associou-se com a relação solidária entre os homens, na busca de construção de seu processo de humanização, traduzindo aspectos da própria organização social, em que todos partilhavam das 
mesmas oportunidades de formação, com a cisão da sociedade em classes, aqueles que se apropriaram de privilégios passaram a utilizar a educação como estratégia de manutenção desta condição de favorecimento, passando a não mais partilhar os conhecimentos que dispunham e a se beneficiar do prolongamento da ignorância daqueles que eram explorados através de seu trabalho.

A afirmativa da autora coloca em evidência o aspecto político presente nos processos educativos, nos convidando a um posicionamento crítico e reflexivo que auxilie na compreensão dos compromissos estabelecidos pelas políticas sociais e que colaboram dialeticamente para a superação e para a manutenção de privilégios.

A reformulação da Lei de Execução Penal brasileira (BRASIL, 2011), que articulou os processos educativos e de trabalho à remissão, fortalece o compromisso e a crença no poder transformador da educação. Tal perspectiva é porta de entrada para o desenvolvimento de relações dialógicas entre educadores e educandos, fundamentadas no amor, na humildade, na fé nos seres humanos, na esperança e no pensar crítico (FREIRE, 1987). Esse conjunto de fundamentos se manifesta por caminhos diversos atravessados, necessariamente, pela reflexão que envolve dimensões subjetivas relacionadas aos sujeitos e instituições, com suas visões de mundo, princípios e valores - e objetivas - que dizem respeito às condições materiais de desenvolvimento das ações formativas, postas, inclusive, em termos de legislação.

Com base no exposto, chamamos atenção para o agradecimento que Pássaro Livre deixa expresso para a coordenadora da Educação Prisional, para sua professora e, ainda, para sua esposa, também reconhecida como educadora neste processo:

Um agradecimento à coordenadora, pelo empenho, pela dedicação no EJA, pelo incentivo no sistema prisional. A minha professora que é outra incentivadora, guerreira. Porque eu acho assim pra você sair da sua casa pra ensinar um bocado de detentos, sem nenhuma perspectiva, às vezes sem retorno e com caso de até agressão dentro das cadeias, com pessoas aproveitando às vezes até para fugir, e ela sair de sua casa para ir pra dentro do sistema onde muitos professores do sexo masculino não querem estar ali dentro. Aí vem uma 
mulher guerreira, forte, como a professora daqui de Aracoiaba, que já vi e as vezes converso com ela, são pessoas guerreiras, então é minha gratidão a coordenadora e à minha professora e a minha esposa. Eu acho que essas foram minhas pedras fundamentais para o sucesso da minha subida, me ergueram. Não importa a dificuldade que eu estou tendo, com gastos, pneu, combustível, deslocamento, com peças, depois disso vai vir um retorno, daqui a 9 semestres.

A dimensão experiencial presente nos relatos de Pássaro Livre demonstram a importância que as possibilidades de expressão, no decorrer dos processos formativos, têm para os sujeitos, considerando a oportunidade autoconhecimento instalada no movimento reflexivo. No entanto, importa destacar, também, a pouca valorização destas referências no contexto das políticas educacionais contemporâneas, marcadas por uma perspectiva positivista que se atualiza, valorizando em demasia o que é quantificável e utilizado para a construção de padrões de comparação entre sujeitos e contextos para fins de hierarquização, categorização vertical e exclusão.

Urge, portanto, valorizar o sensível no contexto das políticas públicas, recuperando a vocação emancipatória e humanizadora da educação, a ser mobilizada através do exercício da fala que permite aos diferentes sujeitos atribuírem sentidos e significados às experiências vividas ao longo de suas trajetórias formativas (BONDÍA, 2002).

Partindo da compreensão de que todo conhecimento, é também autoconhecimento, o exercício da expressão das experiências pelos sujeitos, constitui-se, também como exercício de autoria da própria história e da compreensão crítica dos caminhos já percorridos e daqueles a se percorrer.

Os que sabem da minha trajetória, eles sempre comentam. Alguns comentam, que não é <sic> todos que conseguem, e nem todos que pelejam por essa mudança, mas eles me parabenizam, disseram que eu sou guerreiro. Porque não é fácil você dentro do sistema, diante de todos os pensamentos diferentes, não muito bons e que não incentivam, mesmo que eles tenham um sentimento para incentivar eles querem os outros para baixo, porque eles não gostam que os outros se deem bem. Então nós internos eles sempre sabem que dentro de uma unidade no sistema fechado sempre é mais difícil, o Psicológico, não só os psicológicos entre os presos, mas por falta da família e pela presença dos amigos. Aí isso tudo mexe com a pessoa. E a pessoa entrar, estudar, conseguir passar 
e ainda ser agraciado com de entrar numa universidade, as pessoas veem a diferença. Os professores que me ensinam na UNILAB, os que sabem da minha história e da minha trajetória eles sempre comentam que eu sou um eu sou um exemplo, um incentivo, um guerreiro que não é fácil a pessoa passar por um momento deste e conseguir chegar onde eu cheguei e incentivam a não desistir, que eu siga em frente, desistir jamais.

A percepção de Pássaro Livre sobre suas próprias trajetórias anuncia a compreensão da integralidade de cada ser humano que envolve aspectos cognitivos, sociais, afetivos e psicológicos, entre outros. Assim, é importante, mais uma vez ressaltar elementos como a historicidade e o inacabamento dos sujeitos, anunciados por Freire (1996) como referências importantes para planejarmos, materializarmos e avaliarmos a tarefa educativa e nossos próprios processos formativos. Cada um de nós, como eterno aprendiz da vida, é um ser historicamente datado e situado que traz em sua identidade as marcas de seu tempo e que precisa, cada vez mais, compreender criticamente o modo como está no mundo.

Freire (1996, p. 23), abordando a consciência do próprio inacabamento, o faz de maneira bela, mas não menos profunda:

Gosto de ser gente porque, inacabado, sei que sou um ser condicionado mas, consciente do inacabamento, sei que posso ir mais além dele. Esta é a diferença profunda entre o ser condicionado e o ser determinado. A diferença entre o inacabado que não se sabe como tal e o inacabado que histórica e socialmente alcançou a possibilidade de saberse inacabado. Gosto de ser gente porque, como tal, percebo afinal que a construção de minha presença no mundo, que não se faz no isolamento, isenta à influência das forças sociais, que não se compreende fora da tensão entre o que herdo geneticamente e o que herdo social, cultural e historicamente, tem muito a ver comigo mesmo.

O autoconhecimento envolve, também, o conhecimento do contexto da própria existência, das relações dialeticamente tecidas entre a individualidade e a coletividade, entre a igualdade e a diferença, o pensar e o agir, o saber e o sentir, entre tantas outras relações possíveis. Esse movimento integra, também, o passado, o presente e o futuro, numa perspectiva 
prospectiva que permita o entendimento crítico do ontem, para a melhor compreensão do hoje e o melhor planejamento do amanhã.

As experiências vivenciadas, lidas criticamente, permitem aos sujeitos formularem melhor o modo como se relacionam com o conjunto de experiências que compõem a sua existência, permitindo sonhar com os pés no chão, com a cautela reflexiva proposta por Cortella (2014). Assim, encerramos esta sessão do estudo, com os sonhos anunciados por Pássaro Livre: “[...] concluir meu curso que eu estou fazendo de letras. Eu penso em fazer o mestrado, se possível um doutorado e lecionar. É pra isso que eu entrei lá e quando eu sair de lá é isso que eu vou fazer. Meu projeto de vida é esse ser um professor".

\section{Considerações finais}

Ao longo do texto, buscamos situar a EJA como uma modalidade de ensino composta em sua grande maioria por estudantes que vivenciam processos de exclusão social que os distanciam das oportunidades de escolarização desde o período da infância, avançando para a adolescência e a fase adulta. Assim, o público da EJA traz marcas históricas importantes em suas trajetórias, revelando o peso da desigualdade social no seu processo de construção identitária.

Apesar das inúmeras situações limites que impedem esses sujeitos de desenvolverem plenamente seu potencial e mesmo diante dos processos de desumanização a que estão expostos cotidianamente, os educandos de EJA carregam consigo experiências ricas que através da educação configuram-se como possibilidade de crescimento pessoal e profissional, de transformação e de humanização. Nesse sentido, o compromisso dos educadores com a valorização das identidades e da diversidade presentes no contexto da sala de aula, mais do que uma postura pedagógica configura-se como um compromisso político e ético que se materializa tanto nas Escolas de Educação Básica, quanto em outros espaços, como os cárceres em que se encontram pessoas em privação de liberdade.

Verificamos, a partir de reflexões sobre a EJA no contexto das Unidades Prisionais, que esta não deve ser vista como regalia concedida pelo sistema prisional às pessoas privadas de liberdade, mas como uma possibilidade de ressocialização, de ampliação de horizontes, de emancipação 
e humanização. Neste processo, a concepção dialógica de educação e a valorização de sua dimensão estética é capaz de colaborar com processos de autoconhecimento e autoformação gerados a partir do exercício da sensibilidade e da autopercepção dos sujeitos acerca de suas trajetórias de vida e formação.

Pássaro Livre, sujeito com quem dialogamos ao longo do texto, expressa através de suas narrativas, os desafios presentes no processo educativo vivido no cárcere, o exercício de reflexão e sensibilidade através da arte, os contributos das políticas educacionais e do compromisso ético dos educadores para sua inclusão educacional no contexto universitário e a continuidade dos estudos. Revela, ainda, a importância de projetos de vida para a superação das condições desumanas presentes na sociedade brasileira.

\section{Referências}

ALVARES, Sônia Carbonell. Educação estética para jovens e adultos. In: $V$ Seminário Nacional de Formação de Educadores de Jovens e Adultos. Campinas: Unicamp, 2015.

ARAÚJO, Cristiane Brígida de Melo. A educação na Prisão: Reflexões acerca da EJA no processo de ressocialização. 2013. $22 \mathrm{f}$. TCC (Graduação) - Curso de Ciências Biológica, Universidade Estadual da Paraíba, Campina Grande - PB, 2013.

BOBBIO, Norberto. A era dos direitos. 7a Reimp. Trad. Carlos Nelson Coutinho. Rio de Janeiro: Elsevier, 2004.

BONDIA, Jorge Larossa. Notas sobre a experiência e o saber de experiência. In Seminário Internacional de Educação de Campinas. Campinas, 2002.

BRASIL. Lei $n^{\circ}$ 7210, de 11 de julho de 1984, Institui a Lei de Execução Penal. Diário Oficial da União. Brasília - DF, 1984.

BRASIL. Constituição da República Federativa do Brasil. Brasília - DF, 1988.

BRASIL. Lei de Diretrizes e Bases da Educação Nacional (LDB) no 9394/96. Brasília, 1996.

BRASIL. Parecer CEB № 11/2000. Diretrizes Curriculares Nacionais para a Educação de Jovens e Adultos. Brasília, 2000.

BRASIL. Lei 12.289. Dispõe sobre a criação da Universidade da Integração Internacional da Lusofonia Afro-Brasileira - UNILAB e dá outras providências. Brasília, 2010. 
BRASIL. Lei $n^{\circ}$ 12. 433, de 29 de junho de 2011, altera a Lei no 7210, de 11 de julho de 1984 (Lei de Execução Penal), para dispor sobre a remição de parte do tempo de execução da pena por estudo ou por trabalho. Diário Oficial da União. Brasília - DF, 30 jun. 2011.

BRASIL. Lei $n^{\circ}$ 12.711, de 29 de agosto de 2012, dispõe sobre o ingresso nas universidades federais e nas instituições federais de ensino técnico de nível médio e dá outras providências. Diário Oficial da União. Brasília - DF, 30 ago. 2012.

BRASIL. Lei no 13.409, de 28 de dezembro de 2016, Altera a Lei no 12.711, de 29 de agosto de 2012, para dispor sobre a reserva de vagas para pessoas com deficiência nos cursos técnico de nível médio e superior das instituições federais de ensino. Diário Oficial da União. Brasília - DF, 29 dez. 2016.

CAMPOS, Aline. Educação, escola e prisão: o espaço de voz de educandos do Centro de Ressocialização de Rio Claro/SP. 2015. 276 f. Dissertação (Mestrado) - Curso de Mestrado em Educação do Programa de Pós-Graduação em Educação, Universidade Federal de São Carlos, São Carlos, 2015.

CORTELLA, Mário Sérgio. Educação, escola e docência: novos tempos, novas atitudes. São Paulo: Editora Cortez, 2014.

COSTA, Elisangela André da Silva. A educação de jovens e adultos e o direito à educação: concepções e olhares de educadores e gestores escolares a partir das políticas educacionais do município de Horizonte /Ceará. $203 \mathrm{f}$. Tese (Doutorado) - Curso de Doutorado em Educação Brasileira, Universidade Federal do Ceará, Fortaleza, 2014.

DUARTE JÚNIOR, João Francisco. O sentido dos sentidos. Curitiba: Criar, 2001.

DUARTE JÚNIOR, João Francisco. Fundamentos estéticos da educação. Campinas, SP: Papirus, 2002.

FAGUNDES, Sandra da Penha; SOUZA, Rosineide Ferreira Fernandes; CONCEIÇÃO, Deusilha Araújo. A EJA em presídios: A perspectiva de ressocialização. Revista Saberes em Rede, Cuiabá - MT, v. 1, n. 2, p. 9-16. 2012.

FREIRE, Paulo. Extensão ou comunicação? 8ed. Rio de Janeiro: Paz e Terra, 1983.

FREIRE, Paulo. Pedagogia do Oprimido. Rio de Janeiro: Paz e Terra, 1987.

FREIRE, Paulo. A Importância do Ato de Ler: em três artigos que se completam. 22ed. São Paulo: Cortez, 1988.

FREIRE, Paulo. Pedagogia da Autonomia: Saberes necessários para prática educativa. 6. ed. Rio de Janeiro: Paz e Terra, 1996.

GADOTTI, Moacir. Lições de Freire. Revista da Faculdade de Educação. São Paulo - SP, v. 23, n. 1-2, p. 13-24, jan. 1997. 
MEMÓRIAS E NARRATIVAS DO CÁRCERE: TECENDO DIÁLOGOS ENTRE A EDUCAÇĀO DE JOVENS E ADULTOS, A ARTE E A UNIVERSIDADE

IBGE. Pesquisa Nacional de Amostra por Domicílios. Brasília: IBGE, 2017.

JOSSO, Marie-Cristhine. A transformação de si a partir da narração de histórias de vida. In Educação. Porto Alegre/RS, ano XXX, n. 3 (63), p. 413-438, set./dez. 2007.

LARROSA, Jorge. Tremores: escritos sobre experiência. Belo Horizonte: Autêntica Editora, 2014.

NIETZSCHE, Friedrich. A gaia Ciência. São Paulo: Companhia das Letras, 2001.

ORANIZAÇÃO DAS NAÇÕES UNIDAS. Declaração Universal dos Direitos Humanos. Paris: ONU, 1948.

RIOS, Terezinha Azerêdo. Compreender e ensinar: por uma docência da melhor qualidade. 7. ed. São Paulo: Cortez, 2008.

SILVEIRA, Ana Lucia Nobre. Educação e Sustentabilidade: um estudo sobre as práticas laborais sustentáveis com pessoas privadas de liberdade no Maciço De Baturité/CE. Dissertação (Mestrado) - Mestrado Acadêmico em Sociobiodiversidade e Tecnologias Sustentáveis, Universidade da Integração Internacional da Lusofonia Afro-Brasileira, Redenção/CE, 2018.

SILVEIRA, Ana Lucia Nobre; MARTINS, Elcimar Simão; MACHADO, Charliton José. Educação e Sustentabilidade nos Cárceres: reflexão com privados de liberdade no Maciço de Baturité. In: XAVIER, Antônio Roberto; ALCÓCER, Juan Carlos Alvarado; OLIVEIRA, Jangirglédia de (Org.). Educação, Ciências, Tecnologia e Inovação: Estratégias Sustentáveis. Fortaleza/CE: Imprece, 2016. p. $45-61$.

SOARES, Carla Poennia Gadelha. Primeira escola prisional do Ceará: a avaliação da aprendizagem dos alunos privados de liberdade. $258 \mathrm{f}$. Dissertação (Mestrado em Educação). Universidade Federal do Ceará. Fortaleza: UFC, 2015.

SOUZA, Elizeu Clementino de. (Auto) biografia, histórias de vida e práticas de formação. In: NASCIMENTO, A. D.; HETKOWSKI, T. M. (Org.). Memória e formação de professores [online]. Salvador: EdUFBA, 2007.

VECCHIA, Agostinho Mario Dalla. Afetividade: convergência entre educação biocêntrica e a educação dialógica de Paulo Freire. In: Pensamento Biocêntrico, Pelotas, № 02, Jan/Mar 2005, p. 11-34.

Recebido em 29 de abril de 2019.

Aceito em 30 de maio de 2019. 